OPEN ACCESS

Edited by:

Scott T. Allison,

University of Richmond, United States

Reviewed by:

Antonio M. Espín,

University of Granada, Spain Craig Parks,

Washington State University,

United States

*Correspondence:

Gordon T. Kraft-Todd gordon.kraft-todd@yale.edu

Specialty section: This article was submitted to

Organizational Psychology, a section of the journal

Frontiers in Psychology

Received: 25 September 2018

Accepted: 23 January 2019

Published: 05 February 2019

Citation:

Kraft-Todd GT and Rand DG (2019) Rare and Costly Prosocial Behaviors Are Perceived as Heroic.

Front. Psychol. 10:234

doi: 10.3389/fpsyg.2019.00234

\section{Rare and Costly Prosocial Behaviors Are Perceived as Heroic}

\author{
Gordon T. Kraft-Todd ${ }^{1 *}$ and David G. Rand ${ }^{2}$
}

${ }^{1}$ Department of Psychology, Yale University, New Haven, CT, United States, ${ }^{2}$ Management Science, Brain and Cognitive

Sciences, Massachusetts Institute of Technology, Cambridge, MA, United States

Heroism has only recently become a topic of empirical investigation. Existing research suggests a connection between heroism and four well-documented dimensions of human social behavior: (1) the cost incurred by the actor; (2) the benefit provided to the recipient; (3) the perceived frequency (i.e., descriptive normativity); and (4) the perceived expectation to perform it (i.e., injunctive normativity). In a series of exploratory studies (total $N=408$ ), we aim to shed light on how each of these constructs influence lay intuitions about the nature of heroism (i.e., what determines which acts people perceive to be heroic). In Study 1, subjects generated a list of acts they deemed to be heroic. In Study 2, subjects rated the heroicness of the acts from Study 1, revealing considerable variation in the level of heroism. Finally, subjects in Study 3 rated the cost to the actor, the benefit to the recipient(s), the descriptive normativity (i.e., frequency), and the injunctive normativity (i.e., obligatoriness) of ten acts, five of which received particularly high heroism scores in Study 2 ("exemplary" acts of heroism) and five of which received particularly low heroism scores in Study 2 ("ambiguous" acts of heroism). We find that more heroic acts are seen as rarer and more costly to actors-but, interestingly, not more beneficial to recipients or less obligatory. These findings help to illuminate what it means to be seen as a hero, and suggest clear future directions for both empirical and theoretical work.

Keywords: heroism, cooperation, social norms, prosocial behavior, altruism

\section{INTRODUCTION}

Heroism is the original topic of literature, as evidenced by some of the earliest known human writing from approximately $2100 \mathrm{BC}$ in the Epic of Gilgamesh. Yet, an empirical understanding of heroism is only just emerging. This research has variously investigated types of heroism (Franco et al., 2011), functions of heroism (Kinsella et al., 2015a), traits of heroes (Goethals and Allison, 2012), characteristics of heroes (Kinsella et al., 2015b), and gender differences among heroes (Becker and Eagly, 2004), as well as amalgams of these approaches (Riches, 2018). Allison et al. (2016) summarize a number of dichotomies made in the literature which try to distinguish between two classes of heroes (e.g., emergent vs. sustained; Kraft-Todd and Rand, 2016). In light of this research, an early consensus definition of heroism seems to be taking extraordinary action in service of the greater good with personal risk of significant sacrifice (Allison et al., 2016).

Thus articulated, the burgeoning science of heroism appears to sit squarely between two social science literatures: game theory and social norms. Game theory formalizes strategic decisionmaking between individuals by quantifying the costs and benefits at stake in an interaction 
(Von Neumann, 1959). This conceptualization allows for a precise definition of cooperation - an individual paying a cost to give another a benefit - which in turn presents a conundrum: why do people cooperate (Rand and Nowak, 2013)? A particularly challenging problem in game theoretic terms is understanding why an individual would pay a cost to give many others a benefit, i.e., contribute to public goods (Hardin, 1968) - a pressing problem shared by policy-makers in the real world (Kraft-Todd et al., 2015). In the language of game theory, then, the risk of sacrifice in heroism implies a potentially large cost paid by an actor in order to cooperate or contribute to the public good. Heroism thus may be understood as a special case of cooperation in which the actor incurs (or at least risks) a large cost (akin to extreme altruism; Marsh et al., 2014; Rand and Epstein, 2014). Further, there is good reason to believe that assessment of the costs and benefits might be relevant to our perception of heroism. Adults and children use information about the costs and benefits of others' behaviors to make inferences about their character (Jara-Ettinger et al., 2016). As early as 2 years of age, these evaluations affect our preferences for interacting with others (Jara-Ettinger et al., 2015). Thus, ascriptions of heroism may rely on beliefs about the costs and benefits of an actor's behavior.

Social norms are "rules and standards that are understood by member of a group, and that guide and/or constrain social behavior without the force of laws" (Cialdini and Trost, 1998). Two types of social norms are frequently distinguished: descriptive norms, which are about what people think others do; and injunctive norms, which are about what people believe others think they should do. Colloquially, our conception of what is "normal" lies somewhere between our conception of what is descriptively and injunctively normative (Bear and Knobe, 2016). In the language of social norms, then, the extraordinary action that defines heroism is descriptively non-normative (i.e., rare).

Conceptually situated within this overlap of game theory and social norms, four quantifiable dimensions of social perception may help elucidate a clearer empirical understanding of heroic behavior: (1) the cost to the actor; (2) the benefit to the recipient(s); (3) the descriptive normativity of the behavior; and (4) the injunctive normativity of the behavior. In a series of exploratory studies (total $N=408$ ), we aim to discover the extent to which these constructs influence people's perceptions (i.e., lay intuitions) of heroism.

Intuitively, it seems likely that the more a behavior is thought to be heroic, the greater would be the perceived cost to the actor and benefit to the recipient, while the lower would be the descriptive and injunctive normativity of the behavior. We use a "ground-up" approach to the concept of heroism, avoiding a priori assumptions about what "counts" as heroism (similar to the method of Kinsella et al., 2015a). In Study 1, we therefore ask subjects to generate acts of heroism. In Study 2, we ask a separate group of subjects to rate the extent to which these candidate behaviors are heroic. Finally, in Study 3 , we ask yet another group of subjects to rate the extent to which a subset of these candidate behaviors are costly to the actor, beneficial to the recipient, descriptively normative, and injunctively normative.

\section{STUDY 1: SUBJECT-GENERATED ACTS OF HEROISM}

\section{Materials and Methods}

We recruited 102 subjects from the online labor market Amazon Mechanical Turk (mTurk; Horton et al., 2011; Arechar et al., 2017). We did not collect standard demographics such as age and gender, though previous research has shown that this population is more representative than typical student samples (Berinsky et al., 2012), if not representative of the national population (Paolacci and Chandler, 2014). Subjects completed the study in $m=5 \mathrm{~min}$ and were paid $\$ 0.50$ for their participation, commensurate with typical rates on this platform. We prevented subjects from participating repeatedly (both within each study and across studies) by excluding duplicate Amazon worker IDs and IP addresses. Our pre-study procedure (in this and following studies) was to ask subjects to provide their mTurk IDs and transcribe a sentence of difficult-to-read handwritten text (the latter to prevent bot participation and discourage low-effort workers). For Study 1, subjects simply responded to the prompt: "Please name at least 3 and up to 10 real-life acts of heroism" using free-response text boxes.

Data analysis for all studies was completed using STATA 13. Informed and written consent in all studies was obtained from all subjects and was approved by Yale University's Institutional Review Boards protocol 1307012383.

\section{Results and Discussion}

Subjects generated on average $m=4.2$ responses, which were edited for responses which did not answer the question (often because they were the wrong part of speech, e.g., "boldness," "Jon Meis") repeated answers (within subjects), spelling, punctuation, and grammar (see Supplementary Table S1 for complete list of unedited responses). Responses were further edited for simplicity (e.g., generalizing pronouns such as "woman" and "man" to "person") and semantic commonality ("Entering a burning building to save some one" and "Going into a burning building to rescue people"), yielding a list of 80 unique responses (see Table 1). It is worth noting that nearly all behaviors are explicitly prosocial in nature (e.g., contain "saving," "rescuing," "donating," and "protecting," etc.).

Study 1 therefore provided us with a list of potentially heroic behaviors. The purpose of Study 2, then, was to assess lay intuitions about how heroic each of these behaviors is perceived to be.

\section{STUDY 2: VALIDATING CANDIDATE ACTS OF HEROISM}

\section{Materials and Methods}

We recruited 205 subjects from mTurk who did not participate in Study 1. Subjects completed the study in $m=3 \mathrm{~min}$ and were paid $\$ 0.50$ for their participation. Following the same pre-study procedure as in Study 1, subjects rated a randomly selected subset of 20 candidate acts of heroism from the 80 
generated in Study 1 (presented in randomized order) on how heroic they were using two scales (also presented in randomized order): a binary measure of whether the candidate behavior qualified as "Heroic" (1) or "Not heroic" (0), and a continuous measure of the extent to which the candidate behavior was heroic (Likert scale, 1: "Not at all heroic" - 7: "Very heroic"). Thus $m=51$ subjects rated each candidate behavior using both of these scales. These measures were strongly and significantly correlated $(r=0.95, p<0.001)$, so we use the binary measure for ease of exposition, though analyses are robust to using either measure (see Supplementary Figure $\mathbf{S} \mathbf{3}$ for results of Study 3 using the continuous measure).

\section{Results and Discussion}

Across all 80 candidate behaviors, the median percentage of subjects classifying the behaviors as "heroic" was $82 \%$ ( $m=75 \%$; see Figure 1). Thus, subjects from Study 1 appear to have done a satisfactory job of nominating candidate acts of heroism. Critically, however, there was also substantial variation across behaviors in their level of heroism.

TABLE 1 | Edited list of all candidate acts of heroism used as stimuli in Study 2 (80 total).

\begin{tabular}{|c|c|}
\hline \multicolumn{2}{|c|}{ Edited behaviors } \\
\hline A dog fighting off a wild animal to safe his or her owner & Helping wounded people in a terrorist attack \\
\hline A person jumping on a grenade to save fellow soldiers & Jumping onto subway tracks to lift a person to safety \\
\hline A person shielding someone during a shooting & Performing a life-saving surgery \\
\hline Admitting mistakes & Playing it forward (e.g., buying someone else a coffee unprompted) \\
\hline Adopting and raising foster children & Protecting people in immediate danger \\
\hline Assisting the elderly & Pulling a person from beneath a collapsed wall \\
\hline Becoming a rescue worker & Pulling people out of a train wreck \\
\hline Being a first responder in a natural disaster & Pulling someone out of a burning car \\
\hline Being a good parent & Pushing someone out of the way of an oncoming car \\
\hline Cancer patients fighting for their lives & Sacrificing yourself so strangers may live \\
\hline Childbirth & Sacrificing yourself so your children may live \\
\hline Climbing a tree to rescue a pet & Sacrificing yourself so your family may live \\
\hline Confronting a gunman to defend others & Saving a child from being kidnapped \\
\hline Confronting an abusive spouse & Saving a dog from a hot car \\
\hline Conscientious objectors who refuse to go to war & Saving hostages \\
\hline Covering your loved ones with your body as a tornado hits your home & Saving someone from drowning \\
\hline Defending someone from abusive authority figures & Saving someone's life \\
\hline Defending someone from harm & Saving someone's life when it is not your job \\
\hline Donating an organ & Saving someone's life when it is your job (e.g., fireman, emergency room doctor) \\
\hline Donating blood & Utility workers restoring power in the middle of a major storm \\
\hline Fighting wildfires & Working as a policeman \\
\hline Finding a murder suspect & Working as an inner-city school teacher \\
\hline Giving CPR to a person that needs it & Working for a charity \\
\hline Giving someone an interest-free loan when they are poor & Working for a non-profit \\
\hline Going out on the ice to rescue a person who went through the ice & Working in the coast guard \\
\hline Going to a protest against injustice & Working in the military \\
\hline
\end{tabular}

Raw responses from Study 1 (428 total; see Supplementary Table S1) were edited according to which did not answer the question, repeated answers (within subjects), spelling, punctuation, grammar, simplicity, and semantic commonality. 


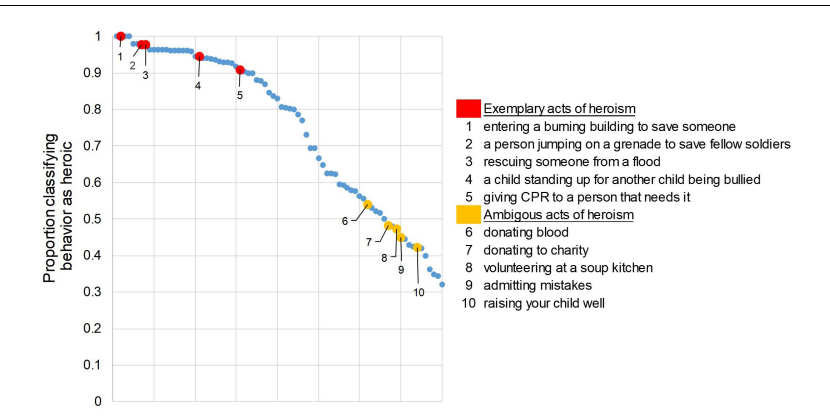

FIGURE 1 | Candidate acts of heroism generated by subjects were broadly (examples in red) or ambiguously (examples in yellow) considered heroic by a separate sample. Shown is a scatterplot of the proportion of subjects rating each of 80 candidate behaviors as "Heroic" (1) or "Not heroic" (0) ranked from most to least heroic. (X-axis represents dummy values for act of heroism).

The goal of Study 3, then, was to understand what explains this variation in heroicness. To do so, we selected ten acts of heroism to investigate in more detail (see Figure 1 legend). We selected five "exemplary" acts of heroism that demonstrated wide consensus on being perceived as heroic (proportion classifying behavior as heroic >0.9) and five "ambiguous" acts of heroism that were not strongly perceived as heroic or not heroic (proportion classifying behavior as heroic $=0.4-0.6$ ). In selecting these behaviors, we focused on behaviors that were frequently discussed in the contexts of cooperation, prosociality, and heroism; and that were specific, rather than sustained, behaviors (with the exception of "raising your child well").

\section{STUDY 3: WHAT DISTINGUISHES ACTS PERCEIVED AS MORE HEROIC?}

\section{Materials and Methods}

We recruited 101 subjects from mTurk who completed the study in $m=5 \mathrm{~min}$ and were paid $\$ 0.50$ for their participation. Following the same pre-study procedure as in Study 1, subjects rated each of the 5 "exemplary" and each of the 5 "ambiguous" heroism behaviors on descriptive normativity ("In your opinion, how many people in your community do this behavior?"), injunctive normativity ("In your opinion, how much do people in your community think doing this behavior is what you are supposed to do?"), benefit to the recipient ("In your opinion, how much benefit (in terms of money, time, effort, etc.) does the recipient of this behavior receive?"), and cost to the actor ("In your opinion, how much cost (in terms of money, time, effort, etc.) does the person who does this behavior incur?"). The 10 behaviors were presented in randomized order and ratings (also presented in randomized order) were completed using sliding scales which ranged from 0 "Very little" to 100 "Very much."

\section{Results and Discussion}

First, we investigate the pairwise correlations among our independent variables (Table 2; Pearson's correlation coefficient,

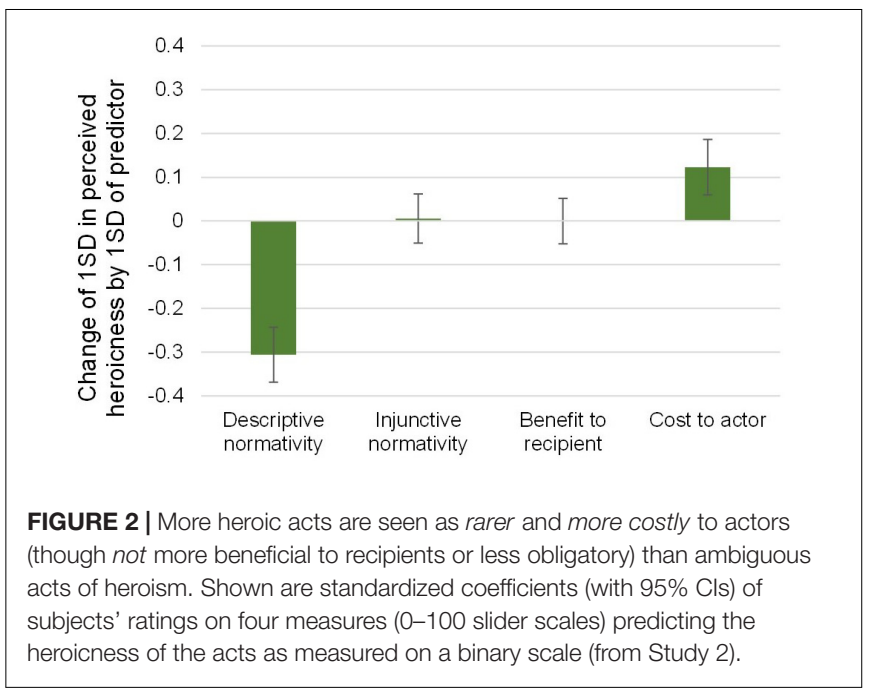

p-values Bonferroni corrected for 6 simultaneous comparisons). Though we observe many significant correlations, they are sufficiently low that it is reasonable to investigate the relationship between heroicness and all independent variables simultaneously in a single model.

Therefore, we investigate differences in perceived heroism based on these four dimensions using OLS regression with proportion of Study 2 participants indicating the behavior was heroic (standardized) as the dependent variable, and (standardized) ratings of costliness, benefit, descriptive normativity, and injunctive normativity as independent variables, clustering standard errors on subject (regression coefficients plotted in Figure 2; see Supplementary Figure S1 for a plot of raw means and Supplementary Figure S2 for distributions). More heroic acts were perceived as less descriptively normative $[b=-0.31,95 \%$ CI $(-0.37,-0.24)$, $t(101)=-9.64, p<0.001]$ and more costly to the actor $[b=0.12,95 \%$ CI $(0.06,0.19), t(101)=3.85, p<0.001]$. However, the heroicness of the acts was not significantly related to perceived injunctive normativity $[b=0.01,95 \% \mathrm{CI}$ $(-0.05,0.06), t(101)=0.20, p=0.843]$ nor perceived benefit to the recipient $[b=-3.27 \mathrm{e}-4,95 \% \mathrm{CI}(-0.05,0.05), t(101)=-0.01$, $p=0.990]$. These results are robust to Bonferroni correction for four simultaneous comparisons (i.e., all significant $p$-values

TABLE 2 | Our dependent variables are significantly, though weakly correlated.

\begin{tabular}{|c|c|c|c|c|}
\hline & $\begin{array}{l}\text { Descriptive } \\
\text { normativity }\end{array}$ & $\begin{array}{l}\text { Injunctive } \\
\text { normativity }\end{array}$ & Benefit & Cost \\
\hline $\begin{array}{l}\text { Descriptive } \\
\text { normativity }\end{array}$ & $x$ & & & \\
\hline $\begin{array}{l}\text { Injunctive } \\
\text { normativity }\end{array}$ & $0.45^{* * *}$ & $x$ & & \\
\hline Benefit & 0.09 & $0.24^{* * *}$ & $x$ & \\
\hline Cost & -0.02 & 0.09 & $0.27^{* * *}$ & $x$ \\
\hline
\end{tabular}


are smaller than 0.0125). Because the continuous ratings of heroicness (our dependent measure) are bimodally distributed (by design), we also demonstrate robustness to conducting this analysis using a logistic regression predicting a categorical dependent variable (exemplary vs. ambiguous acts of heroism; see Supplementary Table S2).

\section{GENERAL DISCUSSION}

Situating an empirical approach to heroism within the game theory and social norms literatures, we conducted three exploratory studies (total $N=408$ ) on lay intuitions of heroic acts. We find that acts which are widely agreed upon as being heroic (exemplary heroism) can be distinguished from acts whose heroicness is unclear (ambiguous heroism), with exemplary acts having lower descriptive normativity and higher costliness to the actor-but not differential injunctive normativity nor benefit to the recipient. These results extend prior work on heroism by providing empirical evidence supporting the conceptual link between the emerging science of heroism and more established fields in the social sciences, while also clarifying the lay definition of heroism.

Our approach avoids being bound by academic preconceptions of heroism by utilizing subject-generated acts of heroism as our stimuli (Study 1, in which we asked, "Please name at least 3 and up to 10 real-life acts of heroism") in subsequent studies. Though a few empirical studies of heroism employ this method, these investigate other aspects of heroism: e.g., "In your view, what functions do heroes serve?" (Kinsella et al., 2015a) and "What are the features that you associate with heroes and their heroic actions?" (Kinsella et al., 2015b). We believe a comprehensive understanding of heroism will be achieved by exploring various means of eliciting lay perceptions of heroism and finding consensus among them.

One major limitation to our investigation is the extent to which our results depend on the specific ten behaviors from Study 2 we chose to serve as stimuli in Study 3. Future research should test the robustness of our conclusions to the consideration of a wider range of heroic acts, and perhaps conduct additional pretesting to ensure candidate acts of heroism do not differ on dimensions (e.g., familiarity) which might affect variables of interest. In particular, the inclusion of candidate acts of heroism with intermediate values of the proportion of people considering them heroic (compared to relative extremes we investigate here) - and the inclusion of acts considered distinctly non-heroic-may shed further light on the relation of perceived heroism and our variables of interest.

Additionally, because our results are drawn from a convenience sample of mTurk workers, they may be culturally specific (in accordance with the WEIRD hypothesis; Henrich et al., 2010). Given that heroism is a socially designated role, it is reasonable to think that lay perceptions of heroism would be influenced by cultural norms; for these reasons, future work might seek to assess this phenomenon cross-culturally. It is worth noting that our investigation is on lay perceptions of heroism, rather than the decision-making process of heroes, and so future work might also explore the extent to which the variables we consider are relevant this process, or whether they are the result of more generalized intuitions (Glanville and Paxton, 2007; Rand and Epstein, 2014). One other potentially interesting question for future research would be to compare first-order beliefs about heroism (as we do here) with second-order beliefs (i.e., what subjects think others think about heroism), as the latter have been demonstrated to have a greater impact on prosocial behavior than the former (Jachimowicz et al., 2018). Finally, our investigation was exploratory, so replication and confirmatory studies should be conducted to provide greater faith in our findings and their interpretation.

We found the observation that exemplary acts of heroism were not perceived as more beneficial to recipients than ambiguous acts of heroism to be surprising, given our intuition that helping others is part what makes an act heroic [e.g., "a person jumping on a grenade to save fellow soldiers" $m=69.0895 \%$ CI $(62.51$, $75.65)$ vs. "volunteering at a soup kitchen" $m=65.84,95 \% \mathrm{CI}$ $(60.53,71.16), t(200)=0.76, p=0.45]$. The within-subjects design of Study 3 grants additional credence to this observation: each subject rated all ten of the heroic acts, and so presumably they could have compared one situation to the next and made these judgments relative to each other. Yet, the finding interestingly coincides with other empirical findings. For example, subjects participating in prisoner's dilemmas are highly influenced by the framing of the situation and potential behaviors, beyond the simple material outcomes of the interaction (e.g., Zhong et al., 2007), and so too here might verbal associations weigh more heavily than numerical assessments in subjects' judgments. In charitable giving, the "effective altruism" movement aims to direct giving toward more socially efficient causes-i.e., get more bang for the donor's buck-yet effectiveness information often does not motivate greater giving (Berman et al., 2018). This finding is an example of the broader phenomenon of scope insensitivity (Carson, 1997), in which people do not exhibit greater valuation for increased amounts of an economic good. Scope insensitivity has been repeatedly demonstrated in the domain of prosociality (Desvousges et al., 1993; Hsee and Rottenstreich, 2004; Small et al., 2007). Thus, our findings are in a sense the converse: while previous research has shown that people do not value (via monetary donations) causes which provide a greater benefit to others, we show that people do not perceive a greater benefit to others from behaviors that are more valued (via judgments of heroism). Further, and more relevant to the characterological judgment nature of heroism, this (non)relation of social benefit to valuation is consistent with findings that people do not prefer consequentialist agents who are willing to inflict harm to provide a greater social benefit (Everett et al., 2018). Taken together, these many potential reasons for our surprising finding that exemplary acts of heroism were not perceived as more beneficial to recipients than ambiguous acts of heroism suggest a promising avenue for future research.

Our finding that judgments of heroism are linked to the cost to the actor but not the benefit to the recipient suggests numerous questions regarding the proximate mechanism of 
heroism perception. First, when a decision-maker is attempting to distinguish whether another's behavior is heroic or not, it could be that the costs to the actor are more salient than the benefits to the recipient if this judgment is accomplished via imagining what it is like to be in the actor's shoes (rather than the recipient's). For example, it could be that when you are trying to decide whether "entering a burning building to save someone" is heroic or not, you engage in perspective-taking not with the person who might be saved, but with the person entering the burning building. Second, it could be that the costs of heroism are simply more observable than the benefits because calculating the latter requires an extra step of contrapositive reasoning: i.e., it requires knowing what would have happened if the hero had not intervened. For example, when a child stands up for another child being bullied, we know that child steps in the way of the bully's fists, but we don't know whether the bully would have broken the victim's nose or just taken their lunch money.

Our finding that judgments of heroism are linked to the descriptive normativity of the action but not the injunctive normativity was also surprising to us, as our intuition was that "going above and beyond" was an important part of being seen as heroic. Our data indicate, however, that this is not the case. Many of the proposed acts of heroism in Study 1 included professions where taking risks to help others is part of the job expectations (e.g., military, firefighter; see Table 1 and Supplementary Table S1). Thus, for these people acting heroically may not be unexpected (i.e., is injunctively normative), but it still may be rare (i.e., is descriptively non-normative). The fact that such actions were still judged to be heroic indicates that unexpectedness (or injunctive normativity) does not appear to be a crucial component of lay perceptions of heroism.

Heroism, understood as rare (i.e., non-normative) and costly cooperation is a particularly timely concept to understand as the need to promote innovative solutions to global social challenges becomes increasingly clear (Kraft-Todd et al., 2018). We hope

\section{REFERENCES}

Allison, S. T., Goethals, G. R., and Kramer, R. M. (2016). "Setting the scene : the rise and coalescence of heroism science," in Handbook of Heroism and Heroic Leadership, eds S. T. Allison, G. R. Goethals, and R. M. Kramer (New York, NY: Routledge). doi: 10.4324/9781315690100

Arechar, A. A., Kraft-Todd, G. T., and Rand, D. G. (2017). Turking overtime: how participant characteristics and behavior vary over time and day on Amazon Mechanical Turk. J. Econ. Sci. Assoc. 3, 1-11. doi: 10.1007/s40881-017-0035-0

Bear, A., and Knobe, J. (2016). Normality: part descriptive, part prescriptive. Cognition 167, 25-37. doi: 10.1016/j.cognition.2016.10.024

Becker, S. W., and Eagly, A. H. (2004). The heroism of women and men. Am. Psychol. 59:163. doi: 10.1037/0003-066X.59.3.163

Berinsky, A. J., Huber, G. A., and Lenz, G. S. (2012). Evaluating online labor markets for experimental research: amazon.com's mechanical turk. Polit. Anal. 20, 351-368. doi: 10.1093/pan/mpr057

Berman, J. Z., Barasch, A., Levine, E. E., and Small, D. A. (2018). Impediments to effective altruism: the role of subjective preferences in charitable giving. Psychol. Sci. 29, 834-844. doi: 10.1177/0956797617747648

Campbell, J. (1949/2008). The Hero With a Thousand Faces. Novato, CA: New World Library.

Carson, R. T. (1997). “Contingent valuation surveys and tests of insensitivity to scope," in Determining the Value of Non-Marketed Goods, eds R. J. Kopp, W. W. our conceptualization of heroism can help connect the emerging science to such pressing real-world issues. Heroism needn't be confined to our cultural mythologies (Campbell, 1949/2008); we may find that we can cultivate it more effectively if we celebrate it in our science as well as in our stories.

\section{DATA AVAILABILITY STATEMENT}

All data are publicly available at: https://osf.io/be8mn/.

\section{AUTHOR CONTRIBUTIONS}

GK-T and DR designed the online experiments. GK-T conducted the online experiments and analyzed the results. GK-T and DR wrote the manuscript.

\section{FUNDING}

This research was made possible by the Defense Advanced Research Projects Agency NGS2 program (Grant No. D17AC00005).

\section{ACKNOWLEDGMENTS}

The authors thank Mark Torres for research assistance.

\section{SUPPLEMENTARY MATERIAL}

The Supplementary Material for this article can be found online at: https://www.frontiersin.org/articles/10.3389/fpsyg. 2019.00234/full\#supplementary-material

Pommerehne, and N. Schwarz (Berlin: Springer), 127-163. doi: 10.1007/97894-011-5364-5_6

Cialdini, R. B., and Trost, M. R. (1998). "Social influence: social norms, conformity and compliance," in The Handbook of Social Psychology, eds S. T. F. D. T. Gilbert and G. Lindzey (New York, NY: McGraw-Hill), 151-192.

Desvousges, W. H., Johnson, R. F., Dunford, R. W., Wilson, N. K., and Boyle, K. J. (1993). "Measuring natural resource damages with contingent valuation," in Contingent Valuation: A Critical Assessment, ed. J. A. Hausman (Bingley: Emerald Group Publishing Limited), 91-164. doi: 10.1016/B978-0-444-814692.50009-2

Everett, J. A. C., Faber, N. S., Savulescu, J., and Crockett, M. J. (2018). The costs of being consequentialist: social inference from instrumental harm and impartial beneficence. J. Exp. Soc. Psychol. 79, 200-216. doi: 10.1016/j.jesp.2018.07.004

Franco, Z. E., Blau, K., and Zimbardo, P. G. (2011). Heroism: a conceptual analysis and differentiation between heroic action and altruism. Rev. Gen. Psychol. 15, 99-113. doi: 10.1037/a0022672

Glanville, J. L., and Paxton, P. (2007). How do we learn to trust? a confirmatory tetrad analysis of the sources of generalized trust. Soc. Psychol. Q. 70, 230-242. doi: 10.1177/019027250707000303

Goethals, G. R., and Allison, S. T. (2012). "Making heroes: the construction of courage, competence, and virtue," in Advances in Experimental Social Psychology, ed. J. M. Olson (New York, NY: Elsevier), 183-235. doi: 10.1016/ B978-0-12-394281-4.00004-0 
Hardin, G. (1968). The tragedy of the commons. Science 162, 1243-1248. doi: $10.1126 /$ science. 162.3859 .1243

Henrich, J., Heine, S. J., and Norenzayan, A. (2010). The weirdest people in the world? Behav. Brain Sci. 33, 61-83. doi: 10.1017/S0140525X0999152X

Horton, J. J., Rand, D. G., and Zeckhauser, R. J. (2011). The online laboratory: conducting experiments in a real labor market. Exp. Econ. 14, 399-425. doi: 10.1007/s10683-011-9273-9

Hsee, C. K., and Rottenstreich, Y. (2004). Music, pandas, and muggers: on the affective psychology of value. J. Exp. Psychol. Gen. 133:23. doi: 10.1037/00963445.133.1.23

Jachimowicz, J. M., Hauser, O. P., O’brien, J. D., Sherman, E., and Galinsky, A. D. (2018). The critical role of second-order normative beliefs in predicting energy conservation. Nat. Hum. Behav. 2, 757-764. doi: 10.1038/s41562-018-0434-0

Jara-Ettinger, J., Gweon, H., Schulz, L. E., and Tenenbaum, J. B. (2016). The naïve utility calculus: computational principles underlying commonsense psychology. Trends Cogn. Sci. 20, 589-604. doi: 10.1016/j.tics.2016.05.011

Jara-Ettinger, J., Tenenbaum, J. B., and Schulz, L. E. (2015). Not so innocent: toddlers' inferences about costs and culpability. Psychol. Sci. 26, 633-640. doi: $10.1177 / 0956797615572806$

Kinsella, E. L., Ritchie, T. D., and Igou, E. R. (2015a). Lay perspectives on the social and psychological functions of heroes. Front. Psychol. 6:130. doi: 10.3389/fpsyg. 2015.00130

Kinsella, E. L., Ritchie, T. D., and Igou, E. R. (2015b). Zeroing in on heroes: a prototype analysis of hero features. J. Pers. Soc. Psychol. 108, 114-127. doi: 10.1037/a0038463

Kraft-Todd, G. T., Bollinger, B., Gillingham, K., Lamp, S., and Rand, D. G. (2018). Credibility-enhancing displays promote the provision of non-normative public goods. Nature 563, 245-248. doi: 10.1038/s41586-018-0647-4

Kraft-Todd, G. T., and Rand, D. G. (2016). "Adaptive foundations of heroism: social heuristics push advantageous everyday ethical behavior to heroic extremes," in Handbook of Heroism and Heroic Leadership, eds S. T. Allison, G. R. Goethals, and R. M. Kramer (New York, NY: Routledge).

Kraft-Todd, G. T., Yoeli, E., Bhanot, S., and Rand, D. G. (2015). Promoting cooperation in the field. Curr. Opin. Behav. Sci. 3, 96-101. doi: 10.1016/j.cobeha. 2015.02.006
Marsh, A. A., Stoycos, S. A., Brethel-Haurwitz, K. M., Robinson, P., Vanmeter, J. W., and Cardinale, E. M. (2014). Neural and cognitive characteristics of extraordinary altruists. Proc. Natl. Acad. Sci. U.S.A. 111, 15036-15041. doi: 10.1073/pnas.1408440111

Paolacci, G., and Chandler, J. (2014). Inside the turk: understanding mechanical turk as a participant pool. Curr. Dir. Psychol. Sci. 23, 184-188. doi: 10.1177/ 0963721414531598

Rand, D. G., and Epstein, Z. G. (2014). Risking your life without a second thought: intuitive decision-making and extreme altruism. PLoS One 9:e109687. doi: 10. 1371/journal.pone.0109687

Rand, D. G., and Nowak, M. A. (2013). Human cooperation. Trends Cogn. Sci. 17, 413-425. doi: 10.1016/j.tics.2013.06.003

Riches, B. R. (2018). What makes a hero? exploring characteristic profiles of heroes using Q-method. J. Humanist. Psychol. 58, 585-602. doi: 10.1177/ 0022167817716305

Small, D. A., Loewenstein, G., and Slovic, P. (2007). Sympathy and callousness: the impact of deliberative thought on donations to identifiable and statistical victims. Organ. Behav. Hum. Decis. Process. 102, 143-153. doi: 10.1016/j.obhdp. 2006.01.005

Von Neumann, J. (1959). On the theory of games of strategy. Contribut. Theory Games 4, 13-42. doi: 10.1515/9781400882168-003

Zhong, C.-B., Loewenstein, J., and Murnighan, J. K. (2007). Speaking the same language: the cooperative effects of labeling in the Prisoner's dilemma. J. Confl. Resolut. 51, 431-456. doi: 10.1177/0022002707300834

Conflict of Interest Statement: The authors declare that the research was conducted in the absence of any commercial or financial relationships that could be construed as a potential conflict of interest.

Copyright (c) 2019 Kraft-Todd and Rand. This is an open-access article distributed under the terms of the Creative Commons Attribution License (CC BY). The use, distribution or reproduction in other forums is permitted, provided the original author(s) and the copyright owner(s) are credited and that the original publication in this journal is cited, in accordance with accepted academic practice. No use, distribution or reproduction is permitted which does not comply with these terms. 